\title{
The Use of Twitter Amongst Female Saudi EFL Learners
}

\author{
Norah K. M. Alsharidi* \\ Department of English, King Saud bin Abdulaziz University for Health Sciences, Saudi Arabia \\ Corresponding Author: Norah K. M. Alsharidi, E-mail: nora-k-sh@hotmail.com
}

\section{ARTICLE INFO}

Article history

Received: February 10, 2018

Accepted: April 21, 2018

Published: July 01, 2018

Volume: 7 Issue: 4

Advance access: May 2018

Conflicts of interest: None

Funding: None

\begin{abstract}
Twitter is a popular microblogging site amongst the Saudi population, which means that Saudi EFL learners are now increasingly connected with millions of native English speakers and other EFL/ESL students. This paper shed light on the use of Twitter by female Saudi EFL learners to determine their English learning practices and their perceptions beyond formal learning contexts. Specifically, the research determined the manner by which the participants' social interactions over Twitter can help with second language (L2) development and the factors that drove them to choose this site to support their L2 learning. To this end, 25 Saudi adult females who were at different levels of study at a local health sciences university in Saudi Arabia were recruited. Underlain by a mixed methods approach, data collection was implemented through survey questionnaires administered to the EFL learners, amongst whom three participated in additional semi-structured interviews. The researcher has provided few recommendations for the future research where use of Twitter in education and its implications for the purpose of teaching.
\end{abstract}

Key words: Twitter, Microblogging Site, Web 2.0, Social Interaction, Authenticity, Conscious, Cubconscious, L2

\section{INTRODUCTION}

Web 2.0 (social software) technologies and innovative electronic devices have become an important part of our daily lives, particularly those of English learners, who are now frequently exposed to the language because of the aforementioned innovations and effectively use them in learning. These modern inventions have engendered new social interaction-oriented language learning avenues, such as e-learning environments, social media platforms and online forums (Mompean \& Fouz-González, 2016). This development also resulted in the establishment of a distinct dimension of TESOL (Teaching English to Speakers of Other Languages) education called mobile-assisted language learning (MALL). MALL was defined by Chaka (2009) as language learning that is mediated by mobile devices. As avenues for social interaction using the target language (i.e. English), mobile devices can promote both unconscious and intentional learning. This functionality enables a shift from passive second language (L2) learning to active L2 use, which also involves language practice for many purposes other than conscious learning, as indicated by Jarvis (2014) in his discussion of mobile-assisted language use (MALU). The informality of learning that is attached to the extensive use of technology in everyday life is an essential component of learning amongst today's students (Rogers, 2004; Bahrani \& Sim, 2012). This essentiality stems from exposure to a target language outside the classroom and the consequent emphasis on meaning, rather than form - an orientation that advances acquisition.

Saudi society is similar to any other contemporary community in that it is characterised by a massive increase in the use of technology and the Internet. Saudi people actively engage with different social media platforms, as indicated in The Economist website, which reported that as of March 2015, Saudi Arabia had the world's highest percentage and strongest base of Twitter users. This finding indicated that Saudi EFL learners are now increasingly connected with millions of native English speakers and other EFL/ESL learners. Saudi learners find the approaches offered by social media interesting given that these platforms enable them to practise language use. Social media afford female Saudi learners of English a growing number of opportunities to interact in L2 with native speakers, their peers and other language learners who share the same or belong to different backgrounds. The ease of access, availability and usability of social media platforms and their potential to offer authentic environments where learners connect and interact with one another using English add to the contributions of social media sites to language learning. As argued by Kukulska-Hulme (2009), social media platforms can function as avenues for English use and practice. This social media-based interaction in L2 
is key to facilitating L2 acquisition because it fosters natural acquisition. This evaluation is consistent with the acquisition perspective of Krashen (1982), who asserted that a conversational environment presents learners with many comprehensible inputs that can help them acquire a language subconsciously. Similarly, Jarvis (2008) suggested that exposure to authentic materials leads to language acquisition.

The current work probed into the above-mentioned issues, with focus on the Saudi Arabian context and particular emphasis on Twitter, which is 'a popular microblogging site' (Levy \& Stockwell, 2006, p. 67). Twitter has seen unwavering global popularity since its launch in 2006. It is a community that keeps users connected to friends and followers and updates users with news. Although not originally designed as an educational tool, the site can serve as one because of its multifunctional nature; that is, 'it is also of as a form of expression, interaction, and community building' (Chartrand, 2012, p. 97).

This research examined the effectiveness of Twitter as a language development medium. Specifically, it determined how Twitter-based English practice amongst female Saudi EFL learners helps promote L2 acquisition and illuminated the aims, goals and reasons behind such usage. There is a need to understand how social media platforms, such as Twitter, can be used to support SLA and how such usage reflects on a user's language learning progress. Another necessary requirement is to comprehend the underlying rationale for using Twitter as a tool for practising English. Satisfying these requirements is important because it will fill the gap in research on the use of one of social media platforms by EFL learners and unravel the ways by which such platform advances subconscious SLA. The following questions were pursued in this study:

- How does interaction over Twitter help female Saudi learners to practise English?

- To what extent is English practice via Twitter reflects in the learning process?

- What are the reasons and factors that drive the use of Twitter as an avenue for English practice amongst learners?

\section{LITERATURE REVIEW}

The implementation of technology cannot be separated from pedagogical or educational theories because a technologically grounded approach is not leveraged in education merely for the sake of technology use; that is, technology is not implemented in a vacuum. Both MALL and MALU, for instance, are oriented towards the adoption of technology, but core differences exist between them in relation to their promotion of L2 acquisition. In explaining certain L2 concepts, two essential second language acquisition (SLA) theories serve as effective frameworks. These theories are Vygotsky's sociocultural theory and Krashen's acquisition/learning hypothesis.

\section{The Use of MALL and MALU}

MALL is underlain by the frequent use of mobile devices. Its advantages lie in the ubiquity of the devices used for educa- tional purposes and the connectivity that such devices enable (Levey \& Stockwell, 2006; Chaka, 2009); it is likewise celebrated for 'its use of personal, portable devices that enable new ways of learning, emphasising continuity or spontaneity of access across different contexts of use' (Kukulska-Hulme \& Shields, 2008, p. 273). The access of ESL/EFL learners to mobile devices outside formal classroom settings removes formality from the learning experience - a feature that may change the way that people learn as electronic language acquisition exposes them to real language (Jarvis, 2008; Walker \& White, 2013). Despite these advantages, however, computer-assisted language learning (CALL) and MALL are criticised for their traditional inclination towards assisted learning that centres on conscious language learning and practice (Bozdoğan, 2015). Other researchers contended, however, that the extensive use of mobile devices transforms learners into active participants and creators of knowledge; it affords them increased control over their learning in online environments that are characterised by an authentic context and audience (Guth \& Petrucco, 2009). The kind of spontaneous, seamless and natural learning that technology-assisted platforms offer corresponds with the reality that language acquisition is a lifelong process (Guth \& Petrucco, 2009). Jarvis and Achilleos (2013) found that learners use English in interactions facilitated by computers and mobile devices not only for academic purposes but also for social aims, whose pursuit advances natural, unconscious acquisition. Jarvis (2014) further explained that learners use language freely and unconsciously over digital devices, thus possibly enabling them to acquire a language rather than merely engaging in deliberate practice. The author also depicted the present educational period as a post-MALL era that features the use of MALU, which may help support language acquisition. The shift from MALL to MALU suggested that devices can have both social and educational functions, thereby presenting students occasions to effectively communicate with a given language in the real world (Kukulska-Hulme, 2009).

\section{Vygotsky's Sociocultural Theory}

Vygotsky's sociocultural theory maintains that learning is a social process that occurs when people interact. The theory was defined by Saville-Troike (2012) as being based on sociolinguistics and psychology, which underlie the role of input and interaction in language learning. This means that interaction drives acquisition and that learning is a social process mediated through language. Being a part of and being present in socially meaningful interactions is essential to learners' progress because such participation supports SLA (De Bot, Lowie, \& Verspoor, 2005). Sociocultural theory underscores the provision of 'an environment in which learners may receive assistance from teachers and peers, as well as participate in negotiated interaction' (Loewen, 2015, p. 9). Such participation in socially meaningful interaction paves the way for assistance. This assistance is called 'scaffolding', which operates under the principle that learners require help in performing certain learning functions before they can accomplish them independently. Scaffolding can 
occur amongst learners, experts and peers. When it takes place during social activities, it becomes a crucial facilitator of SLA because 'languages are learned through socially mediated activities' (Saville-Troike, 2012, p. 123). In the scaffolding process, learners can act as participants or users (Atkinson, 2011).

Similar to the affordances of sociocognitive MALL or MALU, a Web-based environment enables learners to socially engage with other learners from different countries through the use of a target language as a medium of interaction over electronic devices (Jarvis \& Achilleos, 2013; Kern \& Warschauer, 2000; Walker \& White, 2013). Vygotsky's sociocultural theory is applicable as a frame of reference in this study because the core function of Twitter is to usher users towards a social activity, during which they converse, discuss and share ideas and respond to one another (Dunlap \& Lowenthal, 2009). Social interactions that are mediated through a Web-based environment can be described as constituting a zone of proximal development (ZPD) (Guth \& Petrucco, 2009), which is a key concept in Vygotsky's theory (Saville-Troike, 2012). The ZPD was defined by Mitchell and Myles (1998) as the difference between what individuals can do with and without help (scaffolding). A virtual community where learners interact and, simultaneously, assist one another is a fundamental aspect that reflects the ZPD in Vygotsky's sociocultural theory (Antenos-Conforti, 2009; Borau, Ullrich, Feng, \& Shen, 2009). The use of Twitter for MALU enables learners to collectively absorb ideas related to language when they communicate socially in an electronic environment. Such absorption is possible given the negotiation of meaning that advances the acquisition of new aspects of language.

\section{Krashen's Acquisition/Learning Hypothesis}

Collaborative learning and social interaction in L2 may create ideal conditions for the acquisition of language because learners use language in a meaningful context or in an authentic environment instead of practising it in isolation. In this regard, Krashen (1982) developed the acquisition/ learning hypothesis, which distinguishes between implicit L2 knowledge (i.e. 'acquisition') and explicit L2 knowledge (i.e. 'learning') (Ellis, 1997). This distinction, as reflected in electronic environments, is expressed by Jarvis (2008) as encompassed in the terms 'e-second language learning' and 'e-second language acquisition'. The most important element of the acquisition/learning hypothesis is comprehension; an acquirer derives comprehensible input when he/ she is involved in conversations in informal settings, such as Twitter (Bahrani \& Sim, 2012). Learners may thus advance their current L2 proficiency and naturally acquire a new aspect of the language when they interact socially in an online electronic environment (Jarvis, 2015). This is linked to Jarvis's $(2015$, p. 7) perspective on one of the most striking features of MALU-its 'focus on procedural knowledge or learning through language, rather than declarative knowledge or learning about language'.

\section{Social Media as Learning Tools}

Web 2.0 is a term used to refer to users' contribution sites (Walker \& White, 2013). Its use in education has changed the conception of language learning from a process characterised by formal settings to one that is more natural (Guth \& Petrucco, 2009). Web 2.0 technologies are beneficial in terms of providing an authentic environment where learners can express themselves in real language (Chartrand, 2012) given that the main purpose of a learning setting supported by such innovations is to encourage social interaction practice amongst peers for the purpose of naturally and spontaneously generating a target language (Elfatah \& Ahmed, 2015). This authenticity-related advantage is supported by previous research. Studies showed that Web 2.0 technologies provide learners a cooperative and communicative learning environment and promote tolerance, thereby increasing collaboration and interaction in a target language (Antenos-Conforti, 2009; Dippold, 2009; Ducate \& Lomicka, 2008; Kessler, 2009; Tu, Blocher, \& Roberts, 2008; Guth \& Petrucco, 2009). A cooperative learning environment is expected to stimulate knowledge construction in L2 amongst learners. On social media platforms, learners encounter language that has not been simplified or scripted, as is the tendency in classroom-based learning. Guth and Petrucco (2009, p. 425) declared that embracing Web 2.0 technologies and social interaction sites as learning instruments promotes 'social networking on a global scale and knowledge sharing and creation beyond the classroom'. Increased confidence and feelings of comfort is another important benefit of practising English through Web 2.0 tools. Learners need to feel safe in a language learning environment for them to gain experience, absorb knowledge and take risks - actions that contribute to L2 development. The popularity and usability of Web 2.0 amongst EFL learners is attributed to the fact that its services are easy to use, register and update (Ullrich et al., 2008).

Many researchers have shown that educators focus on the use of technology and social interaction with regard to EFL learners (Bahrani \& Sim, 2012; Pemberton, Fallahkhair, \& Mosthoff, 2004; Gao, Luo, \& Zhang, 2012). These scholars stated that social media platforms are windows to the outside world, presenting numerous opportunities to access, use and produce authentic language in real-world contexts (Guth \& Petrucco, 2009) given that English is an international language used by people from different parts of the world to connect with one another (Jarvis \& Achilleos, 2013; Walker \& White, 2013). Walker and White (2013) found that in 2010, English was the most frequently used language over the Internet by more than 536 million users.

The suitability of Twitter as an avenue in which to practise English is supported by a number of studies. Ullrich et al. (2008), for example, found that people use microblogging sites to interact and communicate with others, including native speakers, outside of learning contexts (authentic audience) - a tendency that positively affects their learning process. This result is consistent with that of Gao et al. (2012), who claimed that the informal nature of microblogging sites does not detract from their promotion and support of language learning. Some 
other studies underlined the potential of Twitter to be a convenient environment that positively affects language learning and education (Mork, 2009; Harmandaoglu, 2012; Gao et al., 2012; Bista, 2015; Mompean \& Fouz-González, 2016; Antenos-Conforti, 2009; Borau et al., 2009; Elfatah \& Ahmed, 2015). In an exploration of Twitter as an avenue for learning, Borau et al. (2009) found that the site provides individuals suitable opportunities to practise language use. Tweeting allows them to engage in authentic and creative communication in real-world contexts instead of restricting language use to isolated instances. Other advantages specific to Twitter are that it eliminates fear amongst learners and motivates them to exert effort and produce contributions in L2 (Young, 2010). Writing tweets promotes and enhances the quality of conversations amongst learners who are afraid, shy and unconfident about publicly using a target language (Bart, 2009). Learners are also more comfortable accessing entertainment sites or similar kinds of websites for English use than accessing educational websites for English learning (Jarvis, 2014).

\section{METHODS}

This study used a mixed methods approach, which integrates quantitative and qualitative approaches to data collection and analysis. A mixed methods approach enabled the explanation of the role of technology in promoting L2 on the basis of multiple methods, different worldviews and varying assumptions. The combination of approaches also facilitated the establishment of appropriate and comprehensive arguments regarding the issue of interest. The quantitative and qualitative data revealed the effects of Twitter on the English language learning of the female Saudi EFL participants and their aims and goals for using the site as a medium of interaction for English practice. The questionnaire responses were analysed using the number of Likert-scale ratings to reflect the majority of the responses to each question, and the interview responses were examined through thematic coding.

\section{Participants}

The sample comprised 25 female Saudi students aged 18 to 23 and speak Arabic as their first language. They are at different levels of university education and enrolled in different programmes offered by a local health sciences university for female students. The population of the university reflects the educational system in Saudi Arabia, that is, one formally based on gender separatism. The university offers core English courses at each level, with enrolment in relevant subjects in reading, writing, speaking and listening as a requirement for students to be allowed to proceed with their education in the institution.

As discussed by Perry and Nichols (2004, p. 64), convenience sampling is aimed at a 'conveniently available sample so that it fulfils the purpose of the study'. Thus, the target participants were selected via non-random sampling (convenience sampling) because they were easily available during the summer period for which the study was slated. This decision was also based on the students' willingness to spend some of their time participating in the quantitative and qualitative phases of the research. All agreed to take part in the quantitative phase, but only three were willing to participate in the qualitative phase, as determined from the questionnaire responses.

\section{Research Design}

The quantitative phase of the research involved the administration of an online questionnaire survey (piloted as required). The questionnaire survey was the primary instrument used to collect data (See Appendix 1 for the survey.). The participants were asked to provide answers to 31 questions, which are of closed type and developed on the basis of the research questions. Attitudinal questions were incorporated into the instrument because a crucial requirement was to understand Twitter's functionalities and limitations as a social software application, the ways thorough which the female Saudi EFL learners use the microblogging site and what language they use to interact with one another. To ensure data quality, subjective data (i.e. attitudes, feelings, beliefs, opinions and values with respect to the use of Twitter as a medium of interaction in English) were elicited and extracted using a Likert scale and one 'yes/no' question. The respondents were asked to rate the items on a five-point scale that ranges from 1 ('strongly agree') to 5 ('strongly disagree'); only one statement was intended to delve into usage frequency. Certain statements were paraphrased in more than one way to allow a degree of triangulation.

The qualitative phase entailed semi-structured interviews (piloted and tested as required) consisting of eight questions. The three participants who agreed orally to be part of the interviews were individually spoken to using Skype. The conversations were recorded and transcribed to keep a hard copy (written transcript) and a soft copy (audio recording) of the sessions. Skype sessions were necessary because of the difficulty of conducting face-to-face interviews during the summer vacation. This approach is supported by Dörnyei (2007), who indicated that alternatives to face-to-face interviews, such as a telephone interview, can be implemented should a researcher encounter challenges in arranging personal interviews for any reason. Because no summer courses are offered by the university, the interviews had to be conducted at the convenience of the participants. The structure and wording of the questions and the sequence at which they were presented to the participants were carefully considered to ensure that sufficient answers were derived and bias and leading questions were eliminated. Each individual interview, for which the same question guide was used, lasted more than 20 minutes.

\section{RESULTS AND DISCUSSION}

This section discusses two complementary headings: Social Interaction and Authentic Environment and Unconscious Acquisition. These classifications were chosen because the themes falling under them were commonly encountered in the literature review.Additionally, they also emerged from the multiple data sources that were identified on the basis of the research questions. The participants were aware of the significance of English as an L2 when using technology; 
it is the dominant language or lingua franca over technological platforms, as evidenced by the participants' responses.

\section{Social Interaction and Authentic Environment}

Twitter provides the female Saudi EFL learners the opportunity to behave and think like active users of the English language. This is one of the most important advantages of the collaborative character of the microblogging site. A significant correlation was found between English use outside the classroom and engagement over Twitter. Amongst the respondents, four mostly agreed and 10 agreed with statement 8 (Section 2) regarding the effectiveness of the real language that they are exposed to on the site. Additionally, four mostly agreed and 12 agreed with statement 10 (Section 2) that Twitter is a natural place for practising English because meaningful social interaction occurs on the site. These results confirmed that social interaction over Twitter provides learners with an ideal environment where they can actively practise English instead of being limited to passive reception. As explained by Manal, 'I am connected with the external world more easily on Twitter when I use English. It makes me feel closer to real language and to the people who actually use it'. As can be seen, Twitter paves the way for EFL learners to engage in meaningful interaction in an authentic setting. The female Saudi EFL learners yearn for authenticity as a motivation for exploring genuine language and frequently practising real-world interactions. They endeavour to look for rich sources of authentic English materials so that they can use language in a natural manner and understand how such language is used without the simplification typically implemented in consideration of their competence levels. This statement is reflected in the opinion shared by Sara: 'Twitter, to be honest with you, opened my eyes on how actual natural English is used in real life, which is different from the language we use inside the classroom'.

Of the respondents to statement 4 (Section 2), five mostly agreed and 11 agreed that they are connected to the international arena through English language use on Twitter. Three mostly agreed and 10 agreed with statement 6 (Section 2) on grabbing opportunities to engage in a conversation with people who speak different languages. Maryam expressed her view of herself as being well-blended into the community that uses English to an extent that was previously beyond what was known to her: 'I communicate with a lot of people from different countries and different backgrounds, not only with people I already know'. Twitter enables the learners to expand their circle of contacts to include native speakers of English and other individuals. Additionally, it diminishes the formality and pressure normally encountered in classroom contexts, thereby allowing the participants to improve their confidence. Four mostly agreed and eight agreed with statement 7 (Section 2) regarding the comfort felt in communicating in English over Twitter. Seven mostly agreed and 10 agreed with statement 2 (Section 2) that they feel good about English practice on the site. Learners need to be comfortable for them to believe in themselves and their abilities and for them to elevate their performance in L2. Statement 20 (Section 2) revolves around whether practising English on Twit- ter strengthens the confidence of EFL learners, with which five participants mostly agreed and 11 agreed. As explained by Sara, 'I am more engaged, and I feel this reflected in my confidence in myself and my abilities as I open up to others' opinions. Without any hesitation or fear, I can speak my mind using English, and I am no longer shy'. As can be seen, the female Saudi EFL learners view Twitter as a favourable avenue in which to develop their personality and confidence in the use of the target language.

The data showed that seven participants disagreed and nine participants mostly disagreed with the statement that practising English on Twitter does not offer any benefits. The value of English communication on the site is supported by sociocultural theory, which maintains that language learning results and develops under social interaction. Within social interactions, negotiation of meaning and scaffolding can happen, thereby advancing learning and facilitating SLA. The participants take advantage of this social interactional nature of Twitter to spontaneously use L2. For them, they are producing real and natural language, communicating, sharing ideas and commenting in an authentic setting, making them active participants who have control over their language use. Manal offered the following explanation: 'Although I am using English language in a public environment, there is no pressure or marks, no right or wrong tweets. No one is following my mistakes or judging me. I am just being my natural self with people on Twitter'.

\section{Unconscious Acquisition}

Amongst the participants, 12 mostly agreed, 10 agreed with statement 1 (Section 2) and 3 expressed uncertainty about the issue of unconscious acquisition through the use of Twitter for English practice. The participants indicated that they acquire new vocabulary related to the target language as they engage in digital conversations, with 10 of them mostly agreeing and nine agreeing with statement 14 (Section 2). In addition, 10 of the participants mostly agreed and 12 agreed with statement 19 (Section 2) that practising English on the site helps them learn new aspects of the target language. Maryam's opinion is as follows: 'The interaction that I have with people on Twitter helps me find out about many words, their meanings and how to use them in a conversation'. This accords with the suggestion in the literature that acquiring a target language unconsciously results in the creation of implicit L2 knowledge-a process that is similar to the unconscious acquisition of a first language by a child. The data from the multiple sources highlighted the direct association between the facilitation of social interaction in social media platforms and the incidental or unconscious acquisition of language. This finding is interesting because it corresponds with Krashen's (1982) perspective that L2 learners can pick up a target language once they are involved in a meaningful conversation. Twitter promotes e-second language acquisition via digital interaction, thus exposing learners to language use in an authentic setting with an authentic audience. The same applies to Twitter. Sara explained thus: 'Well, because many words have various indications, when I see one I am not familiar with in a tweet, I try to understand what it means from the context of the sentence? 
In the Saudi Arabian context, especially with respect to female EFL learners, such social interaction in an 'open', informal environment can advance progress in developing English proficiency. This population encounters limited opportunities to practise language use in a natural way. The qualitative data indicated that the participants appreciate the use of Twitter as a medium for English practice because such action manifests authentic learning that is not purposeful, structured and without consciousness.

\section{CONCLUSION AND RECOMMENDATIONS}

This research was aimed at examining whether the use of Twitter as a tool for English practice is reflected in the language development of adult female EFL learners in Saudi Arabia. The participants are native Arabic speakers, whose feelings, attitudes and opinions regarding Twitter as a learning tool were identified in this work. English practice is critical for ESL/EFL learners to develop and improve their language proficiency. The findings showed that the learners' use of L2 in communicating over Twitter is not intended for educational purposes but mainly for social purposes in an uncontrollable environment. Nevertheless, the participants demonstrated that they manage participation on the site in a way that allows them to appropriately use both L1 and L2.

The findings revealed that the participants generally appreciate access to an authentic environment and content as an important part of language development and practice. As indicated in the data, the learners believe that their use of Twitter to practise the target language exposes them to genuine contexts and audiences and that exposure to social engagement facilitates their language development. The nature of Twitter is that it allows learners to interact with other people in a collaborative setting. Most of the EFL learners value the site because of the freedom and flexibility that they can exercise in using L2 in a real-world context. This indicates that learning mostly occurs in an informal setting that extends beyond the confines of a classroom; in this environment, a learner's goal in using English is to adopt it 'as and when required because it was the means to an end' (Jarvis, 2014, p. 28).

Practising the language on the site enhances incidental or unconscious acquisition. The fact that the participants engage in synchronous social interaction allows them to use the target language anytime, anywhere, as is the case with normal conversations. The ubiquity of mobile devices in terms of ownership and usage has eased exposure to comprehensible input and authentic settings as well as natural language acquisition.

As shown by the positive findings regarding the relationship between Twitter and SLA, language instructors are responsible for encouraging increased participation in Twitter activities; many practitioners are unaware of its value as a teaching and learning tool. Practitioners and educators should develop an awareness of the $21^{\text {st }}$ century abilities that students need to refine their use of these innovations. These goals are expected to be achievable given the availability of many online platforms for this purpose. Practitioners and educators should likewise encourage language learners to exert considerable effort in finding tech- nology-based methods of reinforcing their language learning and education.

Within the field of L2 research, many studies have focused on the use of CALL/MALL to facilitate language learning consciously in formal settings. Future research on this phenomenon is needed to illuminate the effectiveness of mobile devices as avenues for learning English unconsciously and go 'beyond a superficial understanding of mobile learning' (Kukulska-Hulme, 2009, p. 164). Although this study endeavoured to fill the gap in the literature on Twitter usage by EFL learners and subconscious language acquisition over mobile innovations, the results were based primarily on the participants' responses, which were limited because of time constraints; the study needed to be completed within three months. Thus, there is a need to more accurately investigate and measure L2 acquisition via Twitter. Researchers should also conduct empirical and experimental studies to precisely determine the SLA outcomes and achievements obtained from social media usage. This direction is important because the concept of subconscious L2 learning is a controversial issue in the TESOL field (Ellis, 1997).

\section{REFERENCES}

Antenos-Conforti, E. (2009). Microblogging on Twitter: Social networking in intermediate Italian classes. In L. Lomicka \& G. Lord (Eds.), The next generation: Social networking and online collaboration in foreign language learning (pp. 59-90). San Marcos, TX: CALICO.

Atkinson, D. (Ed.) (2011). Alternative approaches to second language acquisition. UK: Taylor \& Francis.

Bahrani, T. \& Sim, T.S. (2012). Informal language learning setting: Technology or social interaction? The Turkish Online Journal of Educational Technology, 11(2), pp. 142-149.

Bart, M. (2009, June). Using Twitter to facilitate classroom discussions. Faculty Focus. Retrieved from http://www. facultyfocus.com/articles/effective-teachingstrategies/ using-twitter-to-facilitate-classroom-discussions

Bista, K. (2015). Is Twitter an effective pedagogical tool in higher education? Perspectives of education graduate students. Journal of the Scholarship of Teaching and Learning, 15(2), pp. 83-102. doi:10.14434/josotl.v15i2.12825

Borau, K., Ullrich, C., Feng, J. J., \& Shen, R. M. (2009). Microblogging for language learning: Using Twitter to train communicative and cultural competence. In $\mathrm{M}$. Spaniol, Q. Li, R. Klamma, \& R. W. Lau (Eds.), International Conference on Web-based Learning 2009 (pp. 78-87). Berlin, Germany: Springer Verlag.

Bozdoğan, D. (2015). MALL revisited: Current trends and pedagogical implications. Procedia-Social and Behavioral Sciences, 195, pp. 932-939. doi:10.1016/j.sbspro.2015.06.373

Chaka, C. (2009). Portable handheld language learning: From CALL, MALL to PALL. In P. Torres \& R. Marriot (Eds.), Handbook of Research on E-learning Methodologies for Language Acquisition (pp. 539-552). Hershey, NY: Information Science Reference.

Chartrand, R. (2012). Social networking for language learners: Creating meaningful output with Web 2.0 tools. Knowledge Management \& E-Learning: An International Journal, 4(1), pp. 97-101. 
Dippold, D. (2009). Peer feedback through blogs: Student and teacher perceptions in an advanced German class. ReCALL, 21(1), pp. 18-36.

Dörnyei, Z. (2007). Research methods in applied linguistics. Oxford: Oxford University Press.

Ducate, C. L. \& Lomicka, L. L. (2008). Adventures in the blogosphere: From blog readers to blog writers. Computer Assisted Language Learning, 21(1), pp. 9-28. doi:10.1080/09588220701865474

Dunlap, J. C. \& Lowenthal, P. R. (2009). Tweeting the night away: Using Twitter to enhance social presence. Journal of Information Systems Education, 20(2), pp. 129-135. Retrieved from http:/www.fp.ucalgary.ca/maclachlan/ EDER_679.06_Fall_2009/tweeting_the_night_away.pdf

De Bot, K., Lowie, W., \& Verspoor, M. (2005). Second language acquisition: An advanced resource book. New York: Routledge.

Ellis, R. (1997). Second language acquisition (Oxford introduction to language study series) ( $1^{\text {st }}$ ed.). Oxford: Oxford University Press.

Elfatah, M. A. \& Ahmed, A. S. (2015). The effect of Twitter on developing writing skill in English as a Foreign Language. Arab World English Journal, Special Issue on CALL No. 2, pp. 134-149.

Gao, F., Luo, T., \& Zhang, K. (2012). Tweeting for learning: A critical analysis of research on microblogging in education published in 2008-2011. British Journal of Educational Technology, 43(5), pp. 783-801. doi:10.1111/ j.1467-8535.2012.01357.x

Guth, S. \& Petrucco, C. (2009). Social software and language acquisition. In R. de Cássia Veiga Marriott \& P. Lupion Torres (Eds.), Handbook of Research on E-learning Methodologies for Language Acquisition (pp. 424-442). Hershey, NY: Information Science Reference.

Harmandaoglu, E. (2012). The use of Twitter in language learning and teaching. In A. Colibaba, M. Vlad, \& and C. Colibaba (Eds.), Proceedings of the $5^{\text {th }}$ Edition of the ICT for Language Learning Conference. Florence: Libreria Universitaria Publishing House.

Jarvis, H. (2008). Computers and independent study: Practices and perceptions of students. In P. Torres \& R. Marriot (Eds.), Handbook of Research on E-learning Methodologies for Language Acquisition (pp. 367-386). Hershey, NY: Information Science Reference.

Jarvis, H. (2014). Digital residents: Practices and perceptions of nonnative speakers. Asian EFL Journal Teaching Articles, 75, pp. 21-35. Retrieved from http://www. tesolacademic.org/msworddownloads/AsianEFL\%20 (March14).pdf

Jarvis, H. (2015). From PPP and CALL/MALL to a praxis of task-based teaching and mobile assisted language use. TESL-EJ, 19(1), pp. 1-9. Retrieved from http://tesl-ej. org/pdf/ej73/a1.pdf

Jarvis, H. \& Achilleos, M. (2013). From computer assisted language learning (CALL) to mobile assisted language use. TESL-EJ, 16(4), pp. 1-18. Retrieved from http:// www.tesl-ej.org/wordpress/issues/volume16/ej64/ ej64a2
Kern, R. \& Warschauer, M. (2000). Network-based language teaching: Concepts and practice. New York: Cambridge University Press.

Kessler, G. (2009). Student-initiated attention to form in Wiki-based collaborative writing. Language Learning \& Technology, 13(1), pp. 79-95.

Krashen, S., (1982). Principles and practice in second language acquisition. Oxford: Pergamon Press.

Kukulska-Hulme, A. (2009). Will mobile learning change language learning? ReCALL, 21(2), pp. 157-165.

Kukulska-Hulme, A. \& Shield, L. (2008). An overview of mobile assisted language learning: From content delivery to supported collaboration and interaction. ReCALL, 20(3), pp. 271-289.

Levy, M. \& Stockwell, G. (2006). Call dimensions: Options and issues in computer assisted language learning. US: Lawrence Erlbaum Associates.

Loewen, S. (2015). Introduction to instructed second language acquisition. New York: Routledge.

Mompean, J. A. \& Fouz-González, J. (2016). Twitter-based EFL pronunciation instruction. Language Learning and Technology, 20(1), pp. 166-190.

Mitchell, R. \& Myles, F. (1998). Second language learning theories. London: Arnold.

Mork, C. (2009). Using Twitter in EFL education. The JALT CALL Journal, 5(3), pp. 41-56. Retrieved from http:// journal.jaltcall.org/articles/5_3_Mork.pdf

Pemberton, L., Fallahkhair, S., \& Masthoff, J. (2004). Towards a theoretical framework for informal language learning via interactive television. In D. Kinshuk, G. Sampson, \& P. Isaias (Eds.), Cognition and Exploratory Learning in the Digital Age (CELDA 2004) (pp. 27-34). Lisbon: IADIS Press.

Perry, F. L. \& Nichols, J. D. (2004). Understanding research in education: Becoming a discerning consumer. Routledge: New York.

Rogers, A. (2004). Looking again at non-formal and informal education - Towards a new paradigm. Retrieved June 25, 2016, from www.infed.org/biblio/non_formal_paradigm.htm

Saville-Troike, M. (2012). Introducing second language acquisition ( $2^{\text {nd }}$ ed.). UK: Cambridge University Press.

Tu, C., Blocher, M., \& Roberts, G. (2008). Constructs for Web 2.0 learning environments: A theatrical metaphor. Educational Media International, 45(4), pp. 253-269.

Ullrich, C., Borau, K., Luo, H., Tan, X., Shen, L., \& Shen, R. (2008). Why web 2.0 is good for learning and for research: principles and prototypes. Proceeding of the AMC'S $17^{\text {th }}$ International Conference on World Wide Web (pp. 705-714). Beijing, China.

Walker, A. \& White, G. (2013). Technology enhanced language learning: Connecting theory and practice. Oxford: Oxford University Press.

Why Saudis are ardent social media fans. The Economist. Retrieved from http://www.economist.com/blogs/economist-explains/2015/03/economist-explains-21

Young, J. R. (2010). Teaching with Twitter: Not for the faint of heart. Education Digest: Essential Readings Condensed for Quick Review, 75(7), pp. 9-12. 


\section{APPENDIX}

\section{Appendix 1: Questionnaire Data}

All the data were collected from 25 returned questionnaires. The frequencies of responses (i.e., number of participants choosing a given option) are presented in bold type.

\section{Section 1: General aspects of Twitter usage}

1.1. Do you use Twitter?

$$
\text { - } 25 \text { Yes }
$$$$
\text { - } 0 \text { No }
$$

1.2. How often do you use Twitter? (Please choose one answer.)

$$
\begin{array}{lll}
\text { - } & 14 & \text { Everyday } \\
\text { - } & 3 & \text { Most days } \\
\text { - } & 8 & 2-3 \text { times a week } \\
\text { - } & 0 & \text { Never }
\end{array}
$$

1.3 Please indicate whether you strongly agree (A), agree (B), are unsure (C), disagree (D) or strongly disagree (E) with the statements below.

\begin{tabular}{llllll}
\hline I find it easy to create an & A & B & C & D & E \\
account on Twitter. & 17 & 5 & 1 & 0 & 2 \\
It is easy to follow people & A & B & C & D & E \\
with common interests on & 9 & 13 & 2 & 0 & 1 \\
Twitter. & & & & & \\
I am an active user of & A & B & C & D & E \\
Twitter. & 6 & 4 & 7 & 3 & 5 \\
I find it easy to write a & A & B & C & D & E \\
tweet. & 13 & 6 & 5 & 0 & 1 \\
I find it easy to share ideas, & A & B & C & D & E \\
post videos, etc., on Twitter. & 13 & 8 & 3 & 1 & 0 \\
I use Twitter for different & A & B & C & D & E \\
purposes (e.g., educational & 12 & 12 & 1 & 0 & 0 \\
and social). & & & & & \\
I use only Arabic when I & A & B & C & D & E \\
interact on Twitter. & 4 & 2 & 7 & 11 & 1 \\
I use only English when I & A & B & C & D & E \\
interact on Twitter. & 2 & 2 & 1 & 12 & 8 \\
I use both English and & A & B & C & D & E \\
Arabic when I interact on & 12 & 6 & 4 & 2 & 1 \\
Twitter. & & & & &
\end{tabular}

\section{Section 2: English practice and interaction on Twitter} Please indicate whether you strongly agree (A), agree (B), are unsure (C), disagree (D) or strongly disagree (E) with the statements below.

\begin{tabular}{ll}
\hline Using social media, such as Twitter, & A B C D E \\
offers new ways for me to practise & 1210300 \\
English. & \\
$\begin{array}{l}\text { I feel good when I practise English on } \\
\text { Twitter. }\end{array}$ & A B C D E \\
$\begin{array}{l}\text { I dislike the idea of practising English } \\
\text { on Twitter because it does not offer me }\end{array}$ & A B C D E \\
$\begin{array}{l}\text { any benefits. } \\
\text { I am more internationally connected } \\
\text { when I interact in English on Twitter. }\end{array}$ & A B C D E \\
$\begin{array}{l}\text { I like Twitter because I can } \\
\text { communicate in English with different } \\
\text { people from all over the world. }\end{array}$ & 511441 \\
\hline
\end{tabular}

I communicate in English with people

whose first language is anything but

A B C D E

Arabic.

I am more comfortable communicating in English on Twitter.

A B C D E

48841

I am exposed to real language when I

A B C D E

interact in English on Twitter.

410722

I feel no pressure when I make mistakes on Twitter.

A B C D E

64843

I feel that Twitter is a natural place in which to practise English because

A B C D E

412810

there is meaningful interaction amongst people.

I use Twitter to practise English with only my classmates.

I feel that Twitter is an encouraging place to practise English because no one judges my mistakes.

My interactions with people I follow on Twitter improves my English.

A B C D E 07288

A B C D E

19771

A B C D E 89521

I learn new vocabulary when I interact

A B C D E

in English with other people.

109411

I believe my English has improved since I started interacting with people

A B C D E

211831 on Twitter.

It is easy for me to ask if I need help on

A B C D E my English when I use Twitter.

98332

If I read difficult tweets in English, I

A B C D E search for their meanings.

89521

When I interact with a person on Twitter,

A B C D E

I ask him/her to explain unclear ideas.

39931

I believe using Twitter to practise

English helps me learn new English

A B C D E

1012201

language items.

Continuous practise of English on

A B C D E

Twitter strengthens my confidence in using the language.

\section{Appendix 2: Semi-Structured Interview Guidelines}

1. What are the reasons that direct you to practise and use English on Twitter?

2. What do you like or dislike about practising English on Twitter?

3. Do you think using Twitter to practise English helps you in some way? Why? Why not? Please explain your answer.

4. Do you think it is difficult to practise English on Twitter? Why? Why not? Please explain your answer.

5. Once you interact in English with another person and an idea is unclear, do you seek clarification and ask for its meaning? Why? Why not? Please explain your answer.

6. Do you believe that Twitter provides an environment where you can freely practise English? Why? Why not? Please explain your answer.

7. Do you think interacting in English on Twitter connects you with others? Why? Why not? Please explain your answer.

8. Does Twitter use facilitate your language learning? Why? Why not? Please explain your answer. 